\title{
Atherogenic Index of Plasma and Oxidised LDL in Overt Hypothyroidism in North Indian Female Population
}

Vandana Saini, Kamna Singh, Megha Kataria, Amita Yadav* and Ritu Singh

Department of Biochemistry, Lady Hardinge Medical College, New Delhi, India

\begin{abstract}
Introduction: Hypothyroidism is a clinical condition characterized by reduced oxidative metabolism and it is characterised by markedly increased plasma levels of lipid and lipoprotein. There is insufficient data on lipid levels from India in patients with hypothyroid; only a few studies have been performed in north India. We used oxidised LDL and atherogenic index to better understand the risk for atherosclerosis and coronary heart disease in hypothyroidism. So this study has been done in hypothyroidism which represents an important risk factor for atherosclerosis.
\end{abstract}

Aims and objectives: This study was done to study the association of blood lipids, oxidised LDL and atherogenic index of plasma between hypothyroid patients and control.

Material and methods: In the present study 30 hypothyroid patients and 30 healthy controls with no evident disease were included after taking an informed consent. The study was done in the hormone laboratory of a tertiary care hospital of north India. Fasting venous blood samples were obtained and Serum Lipids were measured by standard automated enzymatic techniques. Oxidised LDL was assayed with ELISA technique. Serum TSH, free T4 (ft4) and free T3 (ft3) were assayed using chemiluminescence. Statistical analysis was carried out using SPSS for windows 14.0 software (SPSS Inc.,Chicago, IL, USA).

Result and observation: Hypothyroid patients had statistically significant higher levels of TSH and low levels of ft3 and $\mathrm{ft} 4$. There was a statistically significant decrease in the levels of HDL. The change in the levels of the atherogenic index of plasma (log LogTG/HDL) was also significant statistically ( $p$ value 0.000 ). There was an increase in the levels of oxidised LDL in hypothyroid patients as compared to controls but this was not statistically significant.

Conclusion: The atherogenic index of plasma is better correlated with hypothyroidism and hence it can be used for risk assesment of atherosclerosis in hypothyroid patients. To establish oxidised LDL as a marker further studies are needed.

Keywords: Hypothyroid; Atherogenic index of plasma; Oxidised LDL

\section{Introduction}

Thyroid hormones influence all major metabolic pathways of human body. Thyroid hormones affect the synthesis, mobilization and degradation of lipids. The degradation of lipids is influenced more than the synthesis [1]. In hypothyroidism there is insufficient production of thyroid hormones by the thyroid gland. Biochemically, there is decrease in $\mathrm{T} 4$ and $\mathrm{T} 3$ concentrations which leads to hyper secretion of pituitary TSH and an amplified increase in serum TSH levels is seen $[2,3]$. Thyroid hormones stimulate production of HMG-CoA reductase, which catalyzes the conversion of HMG-CoA to mevalonate, and thus cholesterol synthesis decreased in hypothyroidism $[4,5]$. However, the reverse may also occur, due to the fact that thyroid hormones affect synthesis and breakdown of LDL cholesterol simultaneously [5]. Clinical hypothyroidism is associated with premature atherosclerosis and increased prevalence of coronary disease. This is at least partly due to the lipid abnormalities often found in hypothyroidism [6]. South Asians are known to have lower Total Cholesterol (TC), higher triglyceride (TG) levels, and low concentration of High-Density Lipoprotein (HDL) cholesterol, as compared to their western counterparts [7]. There is insufficient data on lipid levels from India in patients with hypothyroid; only a few studies have been performed in north India [8]. Therefore the present study was planned to evaluate the changes in indices of lipid profile parameters in overt hypothyroid subjects, and to correlate these values with control subjects. We used oxidised LDL and atherogenic index to better understand the risk for atherosclerosis and coronary heart disease in hypothyroidism.

\section{Methodology}

\section{Study population}

The study was conducted on 60 ambulatory subjects of age group 20 to 50 years referred to thyroid clinic in a tertiary care hospital of northern India after being approved by institutional review board. After informed consent, brief clinical history and examination was done to rule out renal disorders, liver disorder, or any other inflammatory condition which would have influenced the parameters under study.

For these analyses, we excluded subjects who were receiving concurrent treatment with drugs that could contribute to hypothyroidism (lithium, amiodarone, or iodine), those receiving antithyroid medication (methimazole or propylthiouracil) for hyperthyroidism and treatment with lipid lowering drugs for dyslipidemia. After overnight fasting, $6 \mathrm{ml}$ venous blood sample was collected. After centrifugation $(10 \mathrm{~min}$ at $3000 \mathrm{x}$ g), serum was divided into aliquots for lipid profile parameters and thyroid function tests (TSH, fT3 and fT4). Both the aliquots were

*Corresponding author: Amita Yadav, Department of Biochemistry, Lady Hardinge Medical College New Delhi-01, India, E-mail: dramita.md@gmail.com

Received September 06, 2013; Accepted October 23, 2013; Published October 25, 2013

Citation: Saini V, Singh K, Kataria M, Yadav A, Singh R (2013) Atherogenic Index of Plasma and Oxidised LDL in Overt Hypothyroidism in North Indian Female Population. Biochem Anal Biochem 2: 141. doi: 10.4172/2161-1009.1000141

Copyright: (c) 2013 Saini V, et al. This is an open-access article distributed under the terms of the Creative Commons Attribution License, which permits unrestricted use, distribution, and reproduction in any medium, provided the original author and source are credited. 
independently analyzed, such that the person analysing lipid profile was unaware of patient's thyroid function test results and vice versa. Sample for lipid profile was analyzed immediately. Samples for thyroid function tests were stored at $-40^{\circ} \mathrm{C}$ until batch analysed.

\section{Lipid profile tests}

Serum Total Cholesterol (TC) was analyzed by enzymatic CHODPAP method and Triglyceride (TG) was estimated by GPO-PAP method using diagnostic kits by Randox Laboratories (Crumlin, United Kingdom) on Synchron CX4 and CX9 autoanalyzer (Beckman Coulter, USA). High Density Lipoprotein Cholesterol (HDL-C) was determined directly using system pack kits from Beckman Coulter. VLDL-C and LDL-C were estimated using the formula of Friedewald [9].

Thyroid function tests: Serum TSH, fT4 and fT3 were assayed using fully automated chemiluminescent immunoassay Access 2 by Beckman and Coulter (USA). Reference intervals provided by the manufacturer were TSH 0.34-5.6 $\mu \mathrm{IU} / \mathrm{L}$, fT3 2.5-3.9 $\mathrm{pg} / \mathrm{mL}$ and serum fT4 0.6-1.12 $\mathrm{ng} / \mathrm{dL}$. The sensitivities of the TSH, fT3, and fT4 were $0.0025 \mu \mathrm{IU} / \mathrm{L}$, $1 \mathrm{pg} / \mathrm{mL}$, and $0.4 \mathrm{ng} / \mathrm{dL}$ respectively. The intra assay coefficients of variation for TSH, fT3 and fT4 were $1.7 \%, 2.7 \%$, and $3.2 \%$, respectively.

After conducting thyroid function tests, subjects having euthyroid state $(\mathrm{n}=30, \mathrm{TSH} \leq 6.0 \mu \mathrm{IU} / \mathrm{ml}$, normal fT3 and fT4 levels) were taken as controls. Patients with TSH levels $\geq 10 \mu \mathrm{IU} / \mathrm{ml}$ and/or abnormally low fT4 and fT3 levels) were taken as overt hypothyroid patients.

\section{Statistical analysis}

Statistical analysis was carried out using SPSS for windows 15.0 software (SPSS Inc, Chicago, IL, USA). Continuous variables were expressed as mean \pm standard error of mean (S.E.M.). Student's $t$ test was applied to the data. The Pearson correlation was used to test whether TSH, fT4 and fT3 was correlated with TC, LDL-C, HDL-C, TG, VLDLC, TC/HDL-C and LDL/HDL-C. P value $<0.05$ was considered statistically significant.

\section{Results}

In our study the levels of fT3 $(2.609 \pm 0.444 \mathrm{ng} / \mathrm{ml}) \& \mathrm{fT} 4(0.4100$ $\pm 0.165 \mathrm{pg} / \mathrm{dl}$ ) were low as compared to the controls (fT33.205 \pm 0.456 \& fT4 $0.943 \pm 0.2895)$ and this decrease was statistically significant (Table 1). The increase in TSH $(40.223 \pm 30.394 \mu \mathrm{IU} / \mathrm{ml})$ levels were statistically significant in hypothyroid patients as compared to the controls $(2.428 \pm 1.210 \mu \mathrm{IU} / \mathrm{ml})$ (Table 1$)$.

The decrease in HDL-C in hypothyroid patients $(28.48 \pm 6.39 \mathrm{mg} /$ dl) was highly significant statistically as compared to the controls $(40.20$ $\pm 5.05 \mathrm{mg} / \mathrm{dl}$ ) (Table 2). The levels of LDL-C were low in hypothyroid $(102.19 \pm 38.38 \mathrm{mg} / \mathrm{dl})$ as compared to controls $(108.52 \pm 17.02 \mathrm{mg} / \mathrm{dl})$ (Table 2). Patients with hypothyroidism had higher levels of oxidised LDL $(2.74 \pm 4.322 \mathrm{mg} / \mathrm{dl})$ as compared to controls $(1.75 \pm 2.39 \mathrm{mg} /$ dl) but this was not significant statistically (Table 2 ). There is not much change in VLDL-C in hypothyroid when compared with controls (Table 2 ). The decrease in the mean level of atherogenic index in hypothyroid $(0.5401 \pm 0.08461)$ was highly significant statistically as compared to

\begin{tabular}{|c|c|c|}
\hline & Control & Hypothyroid \\
\hline TSH $(\mu \mathrm{ll} / \mathrm{ml})$ & $2.428 \pm 1.210$ & $40.223 \pm 30.394^{* *}$ \\
\hline fT4 $(\mathrm{pg} / \mathrm{dl})$ & $0.943 \pm 0.2895$ & $0.4100 \pm 0.165^{\star *}$ \\
\hline fT3 $(\mathrm{ng} / \mathrm{ml})$ & $3.205 \pm 0.456$ & $2.609 \pm 0.444^{\star *}$ \\
\hline
\end{tabular}

Values represent mean \pm S.D. ${ }^{* *} p<0.001,{ }^{*} p<0.05$

Table 1: Comparison between the TSH, FT4 and FT3 values obtained in hypothyroid and controls. controls $(0.6515 \pm 0.24923)$ (Table 2). The increase in HDL-C/ LDL-C ratio $(0.429 \pm 0.645)$ in hypothyroid was not significant statistically as compared to controls $(0.3778 \pm 0.070)$ (Table 2$)$.

In our study on correlation of TSH, fT3 \& fT4 with various lipid profile parameters we found that TSH was negatively correlated with TG, HDL \& oxidised LDL but this was not significant statistically (Table 3). The levels of fT 3 and fT 4 were negatively correlated with cholesterol, TG \& LDL but this was also not significant statistically (Table 3).

On correlation of oxidised LDL with lipid profile parameters we have found that cholesterol and LDL are positively correlated with oxidised LDL and this was significant statistically (Table 4). The levels of HDL were negatively correlated with oxidised LDL but this was also not significant statistically. Correlations of other parameters were not significant statistically. The atherogenic index of plasma Log TG/HDL was positively correlated with cholesterol, TG, LDL, VLDL and negatively correlated with HDL and this was highly significant statistically. The HDL/LDL index was negatively correlated with Log TG/HDL and this was also significant statistically. The levels of oxidised LDL were negatively correlated with Log TG/HDL but this was also not significant statistically (Table 4).

\section{Discussion}

In our study there was highly statistically significant decrease in HDL-C in hypothyroid patients as compared to the controls [10]. The levels of LDL-C were low in hypothyroid as compared to controls. These may be because of the difference in pattern of dyslipidemia in Indian

\begin{tabular}{|c|c|c|c|}
\hline Parameter & control & hypothyroid & P value \\
\hline Hdl & $40.20 \pm 5.05$ & $28.48 \pm 6.39$ & 0.000 \\
\hline Ldl & $108.52 \pm 17.02$ & $102.19 \pm 38.38$ & 0.517 \\
\hline oxd Idl & $1.75 \pm 2.39$ & $2.74 \pm 4.32$ & 0.646 \\
\hline Vldl & $27.98 \pm 4.25$ & $27.77 \pm 14.06$ & 0.102 \\
\hline HDL/LDL & $0.3778 \pm 0.070$ & $0.429 \pm 0.645$ & 0.084 \\
\hline LOG TG/HDL & $0.6515 \pm 0.24923$ & $0.5401 \pm 0.08461$ & 0.000 \\
\hline
\end{tabular}

Values represent mean \pm S.D

Table 2: Lipid parameters in patients of over hypothyroidism vs controls.

\begin{tabular}{|c|c|c|c|c|c|c|}
\hline \multirow{2}{*}{} & \multicolumn{2}{|c|}{ TSH } & \multicolumn{2}{c|}{$\mathbf{f t 4}$} & \multicolumn{2}{c|}{$\mathbf{f t 3}$} \\
\cline { 2 - 7 } & r values & $\mathbf{p}$ value & r values & $\mathbf{p}$ value & r value & p value \\
\hline CHOL & .120 & .567 & -.178 & .396 & -.304 & .139 \\
\hline TG & -.035 & .869 & -.288 & .162 & -.283 & .171 \\
\hline HDL & -.230 & .268 & .010 & .963 & .031 & .884 \\
\hline LDL & .181 & .388 & -.087 & .681 & -.243 & .242 \\
\hline OXD LDL & -.365 & .073 & .337 & .100 & .211 & .312 \\
\hline VLDL & -0.283 & 0.171 & -0.283 & 0.162 & -0.035 & 0.869 \\
\hline $\begin{array}{c}\text { LOG TG/ } \\
\text { HDL }\end{array}$ & 0.618 & 0.105 & 0.298 & -0.217 & 0.229 & -0.250 \\
\hline
\end{tabular}

Table 3: Correlation ( $p$ values) of tests in hypothyroid cases.

\begin{tabular}{|c|c|c|c|c|}
\hline & \multicolumn{2}{|c|}{ oxidised LDL } & \multicolumn{2}{|c|}{ LOG TG/HDL } \\
\hline & r values & $p$ value & r values & $p$ value \\
\hline $\mathrm{CHOL}$ & 0.481 & 0.017 & 0.594 & 0.002 \\
\hline TG & 0.351 & 0.093 & 0.843 & 0.000 \\
\hline HDL & -0.316 & 0.133 & -0.654 & 0.000 \\
\hline LDL & 0.484 & 0.017 & 0.604 & 0.001 \\
\hline VLDL & 0.351 & 0.093 & 0.843 & 0.000 \\
\hline OXD LDL & - & - & -0.140 & 0.505 \\
\hline LOG TG/HDL & 0.434 & 0.034 & - & - \\
\hline HDL/LDL & 0.289 & 0.170 & -0.411 & 0.041 \\
\hline
\end{tabular}

Table 4: Correlation of lipid profile with oxidised LDL and LOG TG/HDL. 
Citation: Saini V, Singh K, Kataria M, Yadav A, Singh R (2013) Atherogenic Index of Plasma and Oxidised LDL in Overt Hypothyroidism in North Indian Female Population. Biochem Anal Biochem 2: 141. doi: 10.4172/2161-1009.1000141

populations [11]. Patients with hypothyroidism had higher levels of oxidised LDL as compared to controls. In hypothyroidism the LDL oxidation process is delayed [12]. There is decrease in the mean level of atherogenic index of plasma in hypothyroidism and it was positively correlated with cholesterol, TG, LDL, VLDL and negatively correlated with HDL. The atherogenic index of plasma can be an important parameter for the risk assessment of atherosclerosis in hypothyroid patients even when the other lipid parameters are not correlating with the disease. The levels of oxidised LDL were negatively correlated with Log TG/HDL but this was also not significant statistically. In the pretext of variations of lipid profile in Indian population further more studies are required to assess the role of oxidised LDL and atherogenic index of plasma in hypothyroid.

\section{References}

1. Pucci E, Chiovato L, Pinchera A (2000) Thyroid and lipid metabolism. Int $J$ Obes Relat Metab Disord 24: S109-S112.

2. Sawin CT, Castelli WP, Hershman JM, McNamara P, Bacharach P (1985) The aging thyroid. Thyroid deficiency in the Framingham Study. Arch Intern Med 145: 1386-1388.

3. Tunbridge WM, Evered DC, Hall R, Appleton D, Brewis M, et al. (1977) The spectrum of thyroid disease in a community: the Whickham survey. Clin Endocrinol (Oxf) 7: 481-493.
4. Muls E, Rosseneu M, Blaton V, Lesaffre E, Lamberigts G, et al. (1984) Serum lipids and apolipoproteins A-I, A-II and B in primary hypothyroidism before and during treatment. Eur J Clin Invest 14: 12-15.

5. Friis T, Pedersen LR (1987) Serum lipids in hyper- and hypothyroidism before and after treatment. Clin Chim Acta 162: 155-163.

6. Klein I (1990) Thyroid hormone and the cardiovascular system. Am J Med 88 631-637.

7. McKeigue PM, Miller GJ, Marmot MG (1989) Coronary heart disease in south Asians overseas: a review. J Clin Epidemiol 42: 597-609.

8. Vandana Saini, Amita Yadav, Sarika Arora, Ritu Singh, Jayashree Bhattacharjee (2012) Association between different degrees of hypothyroidism and serum lipids. Internet Journal of Medical Update 7: 3-8.

9. Friedewald WT, Levy RI, Fredrickson DS (1972) Estimation of the concentration of low-density lipoprotein cholesterol in plasma, without use of the preparative ultracentrifuge. Clin Chem 18: 499-502.

10. Agdeppa D, Macaron C, Mallik T, Schnuda ND (1979) Plasma high density lipoprotein cholesterol in thyroid disease. J Clin Endocrinol Metab 49: 726-729.

11. Misra A, Luthra K, Vikram NK (2004) Dyslipidemia in Asian Indians: determinants and significance. J Assoc Physicians India 52: 137-142.

12. Costantini F, Pierdomenico SD, De Cesare D, De Remigis $P$, Bucciarelli $T$, et al. (1998) Effect of thyroid function on LDL oxidation. Arterioscler Thromb Vasc Biol 18: 732-737. 